\title{
A RARE CASE OF RING FINGER LIPOMA: CASE REPORT
}

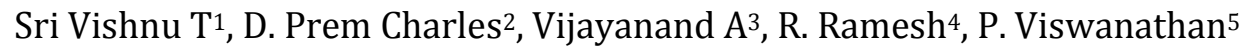

\section{HOW TO CITE THIS ARTICLE:}

Sri Vishnu T, D. Prem Charles, Vijayanand A, R. Ramesh, P. Viswanathan. "A Rare Case of Ring Finger Lipoma: Case Report". Journal of Evolution of Medical and Dental Sciences 2014; Vol. 3, Issue 36, August 18;

Page: 9416-9421, DOI: 10.14260/jemds/2014/3214

ABSTRACT: Lipomas are benign, mesenchymal neoplasms occurring in areas of abundant adipose tissue. ${ }^{1}$ They can be found anywhere in the body with approximately $15-20 \%$ located in the head and neck region and the majority of it rest on the shoulder and back. ${ }^{2}$ They are not very common in the hand and those involving the fingers are extremely rare, with reported incidence of $1 \%$. The first person to report a case of lipoma of the finger was Stein in $1959^{3}$ and since then, 14 cases were identified in the literature. ${ }^{4}$ Of those, 3 cases were on the index finger, 2 cases distal to the right proximal inter phalangeal joint ${ }^{5}$ and 1 case to the left index finger. ${ }^{6}$ All of them were post traumatic in nature. In this report, we present a forty one year old male, with lipoma of the right ring finger.

KEYWORDS: Ring finger, lipoma.

INTRODUCTION: Solitary lipomas, consisting entirely of mature fat, have been largely ignored in the literature, because they grow insidiously and cause few problems other than those of a localized mass. Many lipomas remain unrecorded or are brought to the attention, only if they reach a large size or cause cosmetic problems or complications because of their anatomic site.

As a consequence, the reported incidence of lipoma is certainly much lower than the actual incidence. Even if we consider only the recorded data, lipomas outnumber other benign or malignant soft tissue tumors by a considerable margin and undoubtedly represent the most common soft tissue tumor. This is true for the solitary subcutaneous lipoma and for lipomas in general, regardless of their histologic type.

CASE HISTORY: A forty one year old male presented to the surgical OPD with a swelling in his right ring finger of four years duration. On clinical examination, he had a soft mobile and elastic mass on the dorsal aspect of the third digit of the right hand with no disturbance of sensation. Hence a clinical diagnosis of lipoma was made and excision biopsy was planned.

PROCEDURE: Under local anesthesia (ring block), and the use of tourniquet, we made a linear incision in the dorsal aspect of the finger. The fatty, lobulated mass was found to be localized in the subcutaneous tissue (FIG: 1). The swelling was removed completely avoiding damage to surrounding structures and to the neurovascular bundles and sent for histopathological examination (FIG: 2). 


\section{CASE REPORT}

\section{OPERATIVE IMAGESFRESH SPECIMEN}

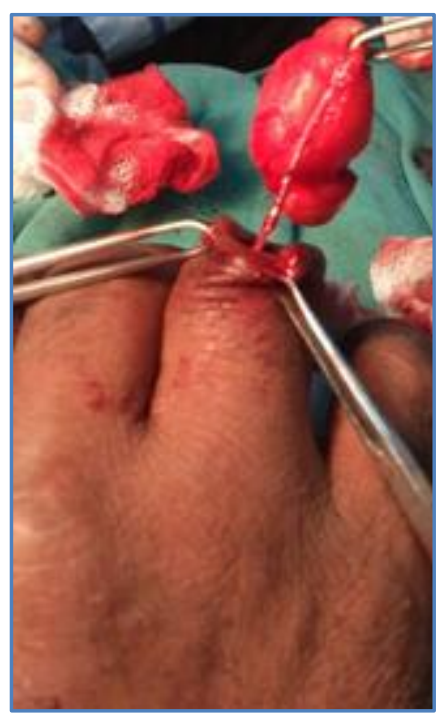

Fig. 1

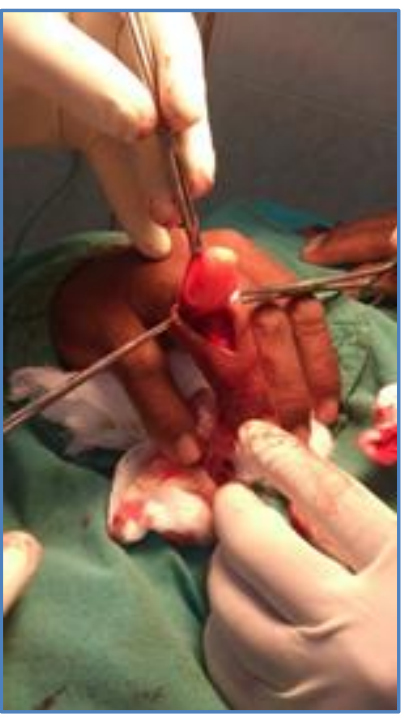

Fig. 2

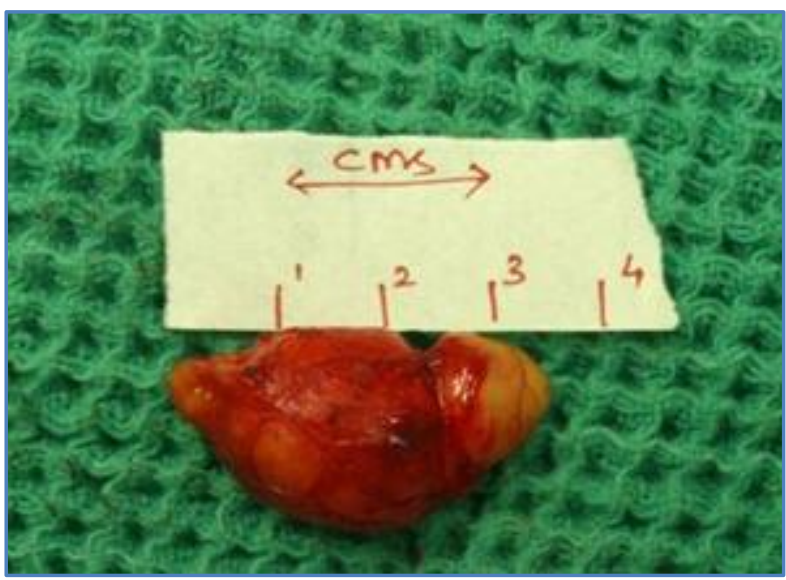

Fig. 3

Macroscopically, the specimen was yellow in color and lobulated, measuring $3.5 \times 2.5 \times 2 \mathrm{~cm}$. On cut-section yellow slimy areas were identified (FIG: $4 \& 5$ ).

\section{FORMALIN FIXED CUT SECTION}

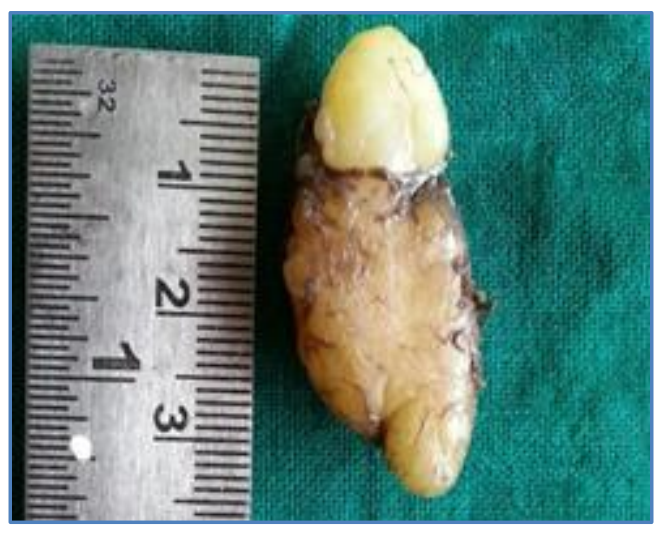

Fig. 4

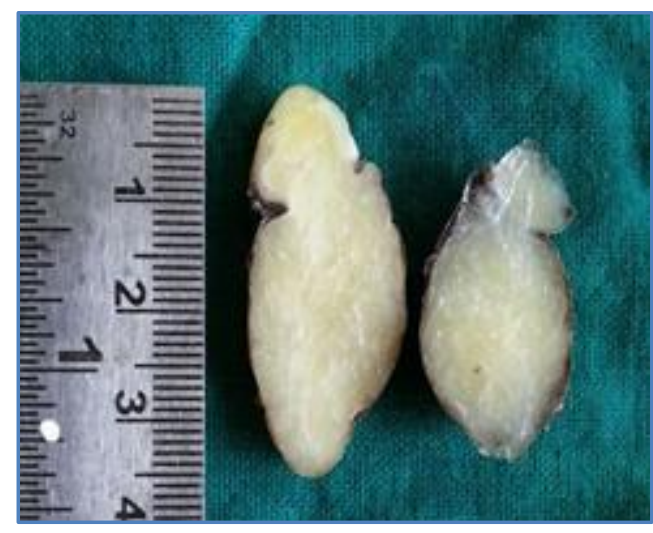

Fig. 5

Microscopically, the tumor was well encapsulated with delicate septa separating the mature adipocytes into lobules (FIG: 6). Close to the capsule there werepericapsular adipocytes (FIG: 7), in between the mature adipocytes there were a proliferation of vessels and fibroblasts (FIG: 7 \& 8). With the above histological features the diagnosis of Fibro lipoma was made. 


\section{CASE REPORT}

\section{MICROSCOPIC PICTURES: H \& E STAIN}

PERICAPSULAR ADIPOCYTES:

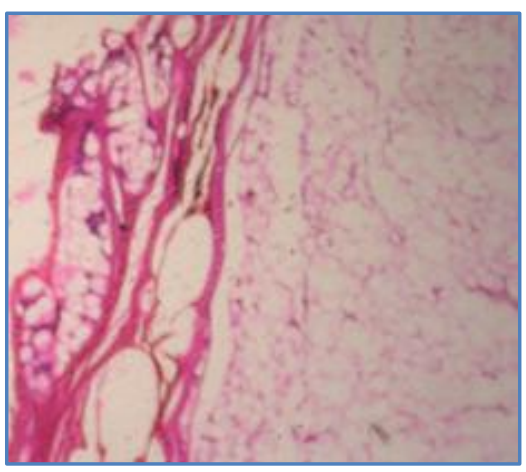

Fig. 6 (A): $4 X$

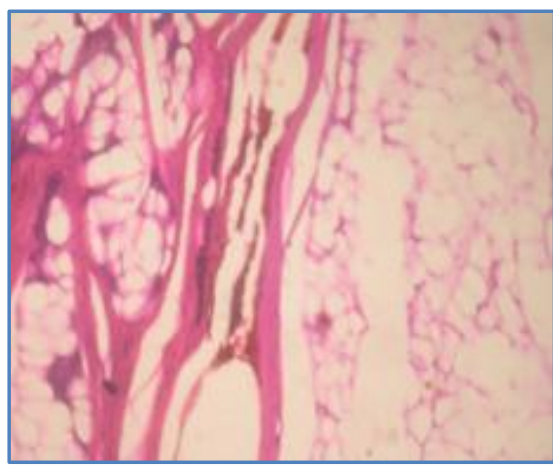

Fig. 6 (B): 10X

WELL ENCAPSULATED TUMOR WITH DELICATE SEPTA SEPARATING THE ADIPOCYTES INTO LOBULES:

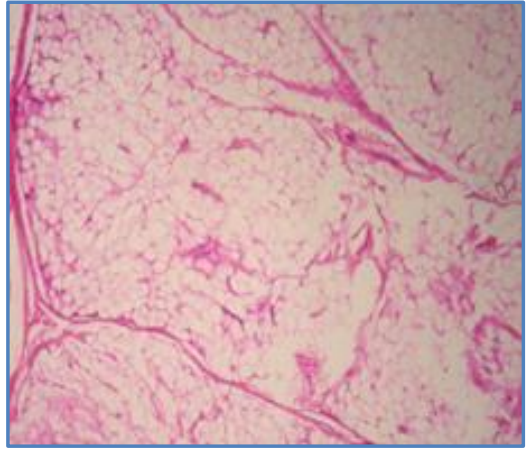

Fig. 7 (A): 4X

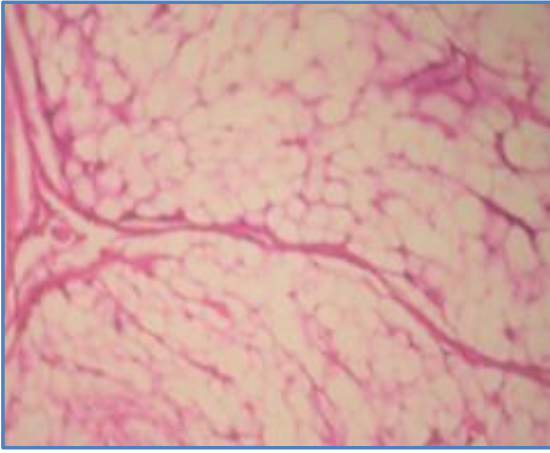

Fig. 7 (B): 10X

PROMINENCE OF FIBROUS TISSUE WITH FEW BLOOD VESSELS:

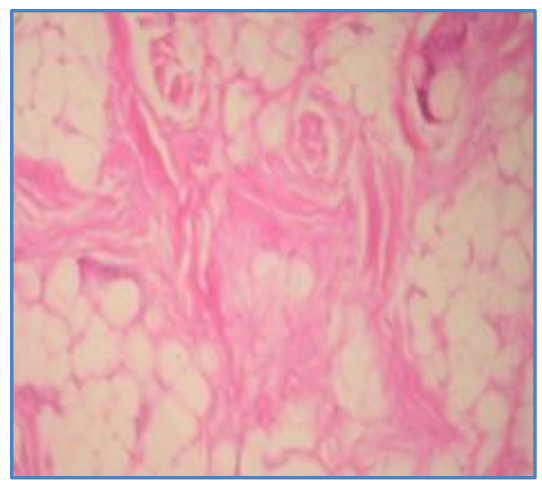

Fig. 8 (A): 10X

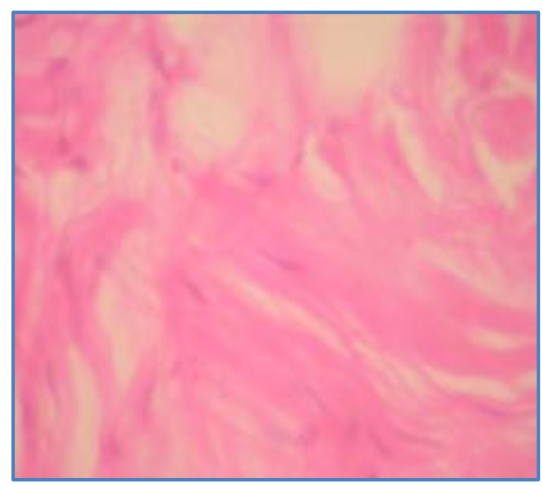

Fig. 8 (B): 40X 
DISCUSSION: Lipomas are rare during the first two decades of life and usually make their appearance when fat begins to accumulate in inactive individuals. Most become apparent in patients between 40 and 60 years of age. Statistics as to gender incidence vary, but most report a higher incidence in men.(7)

Two types of solitary lipoma can be distinguished:

1. Subcutaneous (superficial) lipomas are most common in the regions of the upper back and neck, shoulder, and abdomen, followed in frequency by the proximal portions of the extremities, chiefly the upper part of the arms, buttocks, and upper part of the thigh. They are seldom encountered in the face, hands, lower part of the legs or feet.

2. Deep or subfasciallipomas may cause a variety of symptoms, depending on their site and size. The symptoms range from a feeling of fullness and discomfort on motion and, rarely, restriction of movement with lipomas of the hand to dyspnea or palpitation with mediastinal tumors. Although some benign lipomatous tumors have been described in the retroperitoneum. Most reported in the early literature probably represent well-differentiated liposarcomas rather than lipomas.

Imaging studies are extremely helpful for diagnosis; lipomas present as globular radiolucent masses clearly outlined by the greater density of the surrounding tissue. Computed tomography (CT) scans reveal a mass having the appearance of subcutaneous fat and having a much more uniform density than liposarcomas. On Magnetic Resonance Imaging (MRI) both benign and malignant lipomatous tumors exhibit a high signal intensity on T1-weighted images.(8)

Subcutaneous lipoma usually manifests as a soft, well-circumscribed, thinly encapsulated, rounded mass varying in size from a few millimeters to $5 \mathrm{~cm}$ or more; lipomas larger than $10 \mathrm{~cm}$ are uncommon. On cross-section, the lipoma is pale yellow to orange and has a uniform greasy surface and an irregular lobular pattern. Lipomas of deeper structures vary much more in shape, but they also tend to be well delineated from the surrounding tissues by a thin capsule. Focal discoloration caused by hemorrhage or fat necrosis occurs, but is much less common than in liposarcomas.

Lipomas differ little in microscopic appearance from the surrounding fat as they are composed of mature fat cells. But the cells vary slightly in size and shape and are somewhat larger, measuring up to $200 \mu \mathrm{m}$ in diameter. The nuclei are fairly uniform and importantly, there is an absence of nuclear hyperchromasia. Subcutaneous lipomas are usually thinly encapsulated and have a distinct lobular pattern.

Deep-seated lipomas have a more irregular configuration, largely depending on the site of origin. All are well vascularized, but under normal conditions the vascular network is compressed by the distended lipocytes and is not clearly discernible. The rich vascularity of these tumors becomes apparent in atrophic lipomas in which the markedly reduced volume of the lipocytes reveals the intricate vascular network in the interstitial space.

Lipomas are occasionally altered by an admixture of other mesenchymal elements that comprise an intrinsic part of the tumor. The most common of the elements is the fibrous connective tissue, which is often hyalinized and may or may not be associated with the capsule or the fibrous septa-Fibrolipomas. Sclerotic lipomas have a predilection to occur on the scalp and hands of young men and are composed predominantly of sclerotic fibrous tissue with only focal lipocytic areas. ${ }^{(9)}$ 
Myxolipomasare benign lipomatous tumors that are replaced by mucoid substances that stain well with Alcian blue and are removed or depolymerized by prior treatment of the sections with testicular hyaluronidase.(10) Some of these lesions have an abundance of thin- and thick-walled blood vessels and have been termed vascular myxolipoma or angiomyxolipoma.(11)(12) Distinction of these tumors from myxomasand myxoidliposarcomasmay on occasion be difficult.

In general, the presence of transitional zones between fat and myxoid areas helps rule out myxoma, and the absence of lipoblasts and a diffuse plexiform capillary pattern militates against myxoid liposarcoma. Vacuolated cells containing mucoid material are occasionally seen in myxolipomas and angiomyxolipomas; but unlike neoplastic lipoblasts, these cells lack hyperchromatic nuclei and distinctly outlined lipid droplets within the cytoplasm. Like normal fat cells, the cytoplasmic rim of the fat cells of lipoma is immunoreactive for S-100 protein.

Lipomas are completely benign, but they may also recur locally (fewer than 5\%). Malignant change is virtually unheard of, and only a few cases have been reported in the literature. It is likely, however, that some of them are pleomorphic lipomas, and others are atypical lipomatous tumors (well-differentiated liposarcomas) in which the malignant characteristics were absent or missed when the tumor was first examined. Deep lipomas have a greater tendency to recur, presumably because of the difficulty in complete surgical removal.

CONCLUSION: Although lipomas are universal tumors of the body, lipomas of the fingers are a rare entity. Their awareness is imperative since the differential diagnosis from other soft tissues tumours and from the special lipomatous sub-type involved is quite extensive.

\section{REFERENCES:}

1. Calandruccio JH, Jobe MT: Campbell Operative Orthopaedics St. Louis: Mosby-Year Book, Inc Canale ST, 1998, 4: 3704-3705.

2. Enzinger FM, Weiss SW: Soft tissue tumors St. Louis: Mosby, 3 1995, 381-430.

3. De Giorgi V, Salvini C, Sestini S, Alfaioli B, Carli P: Lipoma of the finger: Acase report and differential diagnosis. Clin Exp Dermatol 2005, 30: 439-440.

4. Stein AH Jr: Benign neoplastic and nonneoplastic destructive lesions inthe long bones of the hand. Surg Gynecol Obstet1959, 109:189-197.

5. Ersozlu S, Ozgur AF, Tandogan RH: Lipoma of the index finger. Dermatol Surg 2007, 33: 382384.

6. Brooks ML, Mayer DP, Grannick MS, Solomon MP, Rhoda CH: Parostealipoma of the finger. Preoperative evaluation with computed tomography. Comput Med Imaging Graphics 1989, 13:481-485.

7. Rydholm A, Berg NO: Size, site and clinical incidence of lipoma. Factors in the differential diagnosis of lipoma and sarcoma. Acta Orthop Scand 1983; 54:929.

8. Munk PL, Lee MJ, Janzen DL, et al: Lipoma and liposarcoma: evaluation using CT and MR imaging. AJR Am J Roentgenol 1997; 169: 589

9. Zelger BG, Zelger B, Steiner H, et al: Sclerotic lipoma: lipomas simulating sclerotic fibroma. Histopathology 1997; 31: 174.

10. Chitnis M, Steyn T, Koeppen P, et al: Differentiation of a benign myxolipoma from a myxoid liposarcoma by tumour karyotyping - a diagnosis missed. Pediatr Surg Int 2002; 18:83. 
11. Lee HW, Lee DK, Lee MW, et al: Two cases of angiomyxolipoma (vascular myxolipoma) of subcutaneous tissue. J Cutan Pathol 2005; 32: 379.

12. Tardio JC, Martin-Fragueiro LM: Angiomyxolipoma (vascular myxolipoma) of subcutaneous tissue. Am J Dermatopathol 2004; 26: 222.

\section{AUTHORS:}

1. Sri Vishnu T.

2. D. Prem Charles

3. Vijayanand A.

4. R. Ramesh

5. P. Viswanathan

\section{PARTICULARS OF CONTRIBUTORS:}

1. $3^{\text {rd }}$ Year Post Graduate, Department of General Surgery, Rajah Muthiah Medical College, Annamalai University, Chidambaram.

2. $3^{\text {rd }}$ Year Post Graduate, Department of Pathology, Rajah Muthiah Medical College, Annamalai University, Chidambaram.

3. $3^{\text {rd }}$ Year Post Graduate, Department of Pathology, Rajah Muthiah Medical College, Annamalai University, Chidambaram.

4. Professor, Department of General Surgery, Rajah Muthiah Medical College, Annamalai University, Chidambaram.
5. Professor, Department of Pathology, Rajah Muthiah Medical College, Annamalai University, Chidambaram.

\section{NAME ADDRESS EMAIL ID OF THE CORRESPONDING AUTHOR:}

Dr. P. Viswanathan,

Professor,

Department of Pathology,

Faculty of Medicine,

Rajah Muthiah Medical College,

Annamalai University,

Chidambaram-608002,

Tamilnadu, India.

Email: drpiswanathan2013@gmail.com

Date of Submission: 02/08/2014.

Date of Peer Review: 04/08/2014.

Date of Acceptance: 12/08/2014.

Date of Publishing: 16/08/2014. 